\title{
Sistem Kendali Kecepatan dan On/Off Penyejuk Ruangan Berbasis Esp8266 Nodemcu V3
}

\author{
Agung Nugroho*1, Hartati Dyah Wahyuningsih ${ }^{2}$, Erni Widarti ${ }^{3}$, Muhammad Rakha S. ${ }^{4}$ \\ ${ }^{1}$ Program Studi Teknik Komputer, STMIK AUB, Surakarta, Indonesia \\ ${ }^{2}$ Program Studi Sistem Informasi, STMIK AUB, Surakarta, Indonesia \\ ${ }^{3,4}$ Program Studi Sistem Komputer, STMIK AUB, Surakarta, Indonesia \\ e-mail: *1agung_new@stmik-aub.ac.id, ${ }^{2}$ hartati.dyah@stmik-aub.ac.id, ${ }^{3}$ erni.widarti@stmik- \\ aub.ac.id, ${ }^{4}$ rakha.jentz@gmail.com
}

\begin{abstract}
Abstrak
Pintu merupakan akses utama untuk memasuki sebuah ruangan atau kamar, efesien si dan kenyamanan dalam penggunaan pintu pula sangat dibutuhkan untuk mempermudah manusia dalam mengakses sebuah ruangan terutama pada saat membawa banyak barang ataupun aktifitas lain yang menyulitkan untuk menggunakan kunci konvensional.

Di Indekos Putri Griya Aluya terdapat dua puluh delapan kamar yang semuanya masih menggunakan kunci konvensional. Karena penggunaan pada anak kunci sering diputar lama kelamaan anak kunci akan rusak karena gerigi pada anakkunci gundul, sehingga pintu tidak dapat dibuka dan terkadang pengguna kamar indekos setelah pulang dari kampung halaman anak kunci tertinggal. Untuk mempermudah pengguna kamar dalam mengakses kamar maka dibuatkan aplikasi android solenoid door lock sehingga pengguna dapat membuka dan mengunci kamar menggunakan smartphone android.

Hasil perancangan aplikasi ini menggunakan metode prototype. Sedangkan untuk menggambarkan alur diagram menggunakan flowchart sistem. Menggunakan aplikasi android studio dan arduino ide dalam pembuatan aplikasi, serta esp32 sebagai mikrokontroler dan solenoid door lock sebagai pembuka dan pengunci. Berdasarkan pengujian yang telah dilakukan menggunakan pintu replika, alat yang sudah dirancang dapat membantu masalah yang dihadapi pada indekos Putri Griya Aluya.
\end{abstract}

Kata kunci-Internet, NodeMCU, ESP8266, Blynk.

The use of the internet has penetrated into all areas of life, one of which is in the field of remote control. The advantage of remote control through the internet network has several advantages, which are not influenced by distance and time. All things can be controlled via the internet. And Generally Air Conditioning in the house is turned on or off manually by pressing a button or remote. With the technology that is developing now makes people want to do things easily. By using Internet of Thing (IoT) Technology. Users can control electrical equipment and for example, air conditioning can be controlled using a control module through the in ternet network. with an android smartphone that is used as a remote control, a smartphone that uses the android operating system and uses the Blynk application. By using NodeMCU V3, microcontroller and relay we can make tools that can control electrical equipment that is connected to the internet so that it is practical in operation because it does notrequire a lot of remote for electrical equipment. 
Keywords - Indekos Putri Griya Aluya, Solenoid Door Lock, Android Studio, Arduino IDE, ESP32

\section{PENDAHULUAN}

Perkembangan jaman dan teknologi, sebagian besar masyarakat telah memanfaatkan sistem internet of things untuk memudahkan aktifitas kehidupannya. Salah satu penopang teknologi yang berkembang secara saat ini adalah listrik. Hampir sebagian besar sarana dan prasarana yang ada menggunakan listrik sebagai sumber penggeraknya. Tanpa listrik manusia tidak akan bisa maju dan berkembang. Listrik telah menjadi kebutuhan pokok manusia, semua bidang kehidupan telah tersentuh oleh listrik, salah satunya adalah dari segi pemanfaatan listrik disegmen rumah tangga. Pemanfaatan energi listrik dirumah tangga sangatlah besar, mulai dari menyalakan lampu untuk penerangan dimalam hari serta untuk menggerakkan peralatan rumah tangga yang lainnya. Sebagian peralatan listrik di kendalikan melalui remot, dan jika menggukan banyak peralatan listrik menambah jumlah remot yang digunakan, maka dari itu Solusi untuk memudahkan pengendalian adalah dengan memasang sebuah alat yang dapat mengendalikan peralatan listrik tersebut dari jarak jauh atau dengan memanfaatkan sistem wireless. Sehingga tidak di butuhkan banyak remot.

Salah satu jenis sistem kendali jarak jauh adalah dengan menerapkan konsep Internet of Things (IoT). Pada dasarnya Internet of Things adalah suatu konsep dimana objek tertentu punya kemampuan untuk mentransfer data lewat jaringan tanpa memerlukan adanya interaksi dari manusia ke manusia ataupun dari manusia ke perangkat komputer.

Sebagai salah satu solusi dari permasalahan tentang pengendalian yang tidak praktis, maka penulis akan merancang sebuah rangkaian yang berfungsi untuk mengendalikan peralatan listrik secara wireless. Maka penulis memberi judul "Sistem Kendali Kecepatan dan On/Off Penyejuk Ruangan Berbasis Blynk ESP8266 NodeMCU”.

\section{METODE PENELITIAN}

\subsection{Penelitian Terdahulu}

Ashari, Lidyawati, 2017 penelitian yang berjudul "IoT Berbasis Sistem Smart Home Menggunakan Nodemcu V3". Penelitian ini bertujuan untuk merancang dan membuat sistem smart home berbasis IoT. Sistem smart home dirancang dengan Pengembangan sistem kontrol dalam implementasinya, menggunakan modul NodeMCU V3 sebagai penghubung ke internet via wifi, modul, relay yang nantinya akan disambungkan dengan perangkat elektronik dan aplikasi blynk melalui smartphone yang akan mengendalikan semua itu. dalam akses dapat diaktifkan dan dimatikan perangkat elektronik melalui smartphone.

Fikriyah, Rohmanu, 2018 penelitian yang berjudul "Sistem Kontrol Pendingin Ruangan Menggunakan Arduino Web Server dan Embedded Fuzzy Logic di PT. Inoac Polytechno Indonesia". Penelitian ini bertujuan untuk merancang sistem kontrol suhu ruang akan sangat bermanfaat pada proses kegiatan bekerja para pegawai industri dan perkantoran menengah yang efisien. Sistem kontrol pendingin ruangan ini dirancang dengan Arduino Uno, berfungsi sebagai penyimpan program yang akan dijalankan. Sensor LM35, berfungsi sebagai pendeteksi suhu ruangan, dan Module ESP8266, berfungsi sebagai penghubung Arduino ke jaringan internet, kemudia Sensor Ultrasonik, berfungsi sebagai penghitung jumlah karyawan yang masuk dan keluar ruangan Sistem ini menggunakan dua variable yaitu suhu ruangan dan jumlah orang, Semakin banyak orang yang masuk kedalam ruangan, maka otomatis kipas akan hidup, ketika orang didalam ruangan berkurang, kecepatan kipas akan berkurang juga, sehingga lebih efisien dalam penggunaan listrik..

Prasetiyo, 2017 penelitian yang berjudul "Aplikasi Internet Of Things (IoT) Untuk Pemantauan dan Pengendalian Beban Listrik di Ruangan”. Penelitian ini bertujuan untuk membuat desain, mengimplementasikan dan mengetahui untuk kerja aplikasi internet of things (IoT) untuk pemantauan dan pengendalian beban listrik di ruangan. Dirancang dengan sistem 
aplikasi IoT untuk pemantauan dan pengendalian beban listrik di ruangan ini, dengan NodeMCU dan ESP8266 sebagai pengendali utamanya.

\subsection{Metode pengumpulan data}

1. Metode Observasi

Dalam observasi peneliti terlibat dengan kegiatan sehari-hari orang yang sedang diamati atau yang digunakan sebagai sumber data penelitian (Sugiyono, 2013). Pengumpulan data dengan melakukan pengamatan secara langsung Pada obyek penelitian untuk melakukan perbandingan dan mengumpulkan data-data yang bisa dipakai sebagai acuan untuk merancang pembuatan alat.

2. Metode Pustaka

Melakukan studi kepustakaan mengenai pembahasan pada setiap komponen yang digunakan beserta skema rangkaian dari refrensi (jurnal). Untuk memperkuat data-data dan masalah yang dihadapi, penulis mencari informasi lewat perpustakaan, internet, buku literatur serta jurnal sebagai referensi untuk melakukan kegiatan penilitian tersebut.

\subsection{Analisis Kebutuhan Sistem}

Analisis kebutuhan sistem adalah kegiatan untuk menyusun segala macam kebutuhan yang harus ada dalam sebuah sistem yang akan dibangun. Baik itu kebutuhan perangkat keras maupun kebutuhan perangkat lunak. Pada analisa kebutuhan dapat diwujudkan atau digambarkan pada sebuah diagram blok dari sistem. Diagram blok sistem menggambarkan blokblok modul / rangkaian dari sistem secara keseluruhan. Penggambaran diagram blok dari sistem perlu untuk dilakukan dengan tujuan agar memudahkan dalam memahami cara kerja dari sistem secara keseluruhan sehingga memudahkan dalam perancangan dan pembuatan alat.

\subsection{Diagram Blok sistem}

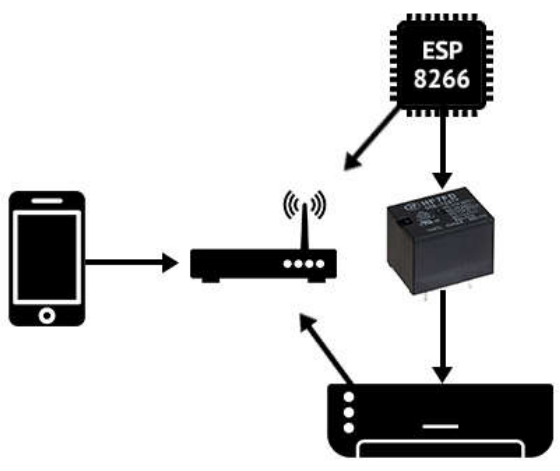

Gambar 1. Diagram blok sistem

Penjelasan dari Gambar 1 adalah sebagai berikut. Komunikasi antara smartphone dengan modul ESP8266 dilakukan melalui jaringan internet. Smartphone melalui aplikasi blynk mengirim data ke internet ke server blynk. Data dari server blynk kemudian diteruskan ke modul ESP8266 melalui jaringan wifi. Sampai di modul ESP8266 data tersebut digunakan untuk mengendalikan kecepatan dari putaran angin / blower dari Penyejuk ruangan.

\subsection{Flowchart Sistem Penyejuk ruangan}

GO INFOTECH: JURNAL ILMIAH STMIKAUB Vol. 26, No. 2, Desember 2020: 186-193 


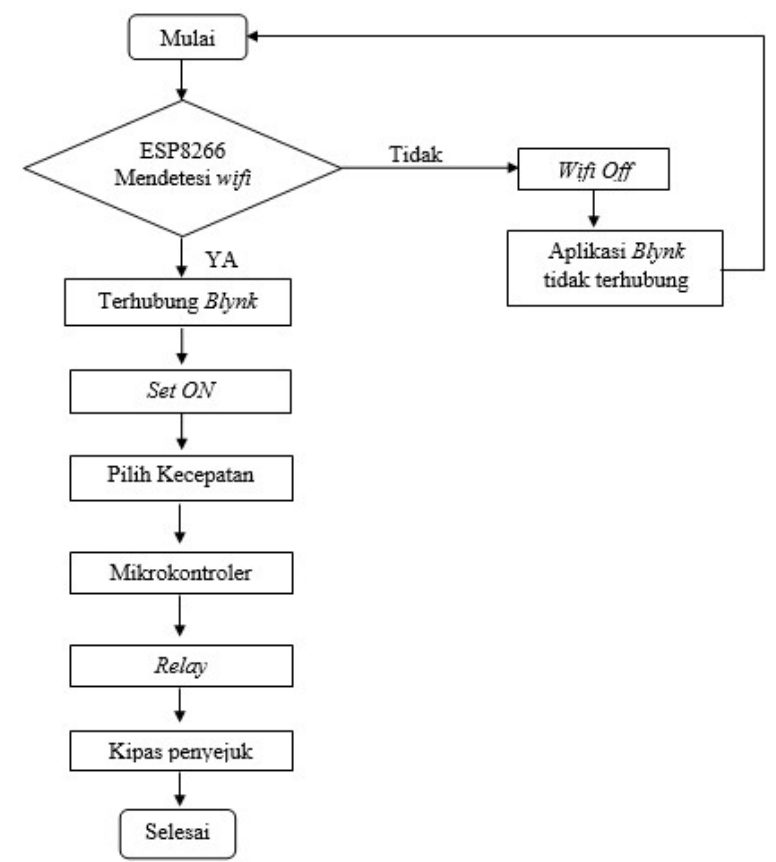

Gambar 2. Flowchart Sistem

Penjelasan Flowchart Berikut :

1. Jika ESP8266 terhubung ke Internet, maka ESP8266 juga terhubung dengan server Blynk. Jika tidak terhubung dengan internet maka tidak bisa untuk berkomunikasi dengan smartphone.

2. Jika Sudah terhubung maka aplikasi Blynk di smartphone akan muncul notifikasi penyejuk ruangan sedang online.

3. Jika sudah memilih tombol $O N$ di aplikasi Blynk smartphone maka penyejuk ruangan akan dalam posisi stanby.

4. Pada saat setelah melilih kecepatan penyejuk ruangan maka mikrokontroler akan menyalakan hambatan relay sesuai dengan kecepatan yang dikehendaki

5. Jika Sudah memilih kecepatan maka relay akan menyesuaikan hambatan sesuai dengan permintaan kecepatan yang ada di aplikasi blynk pada smartphone.

6. Sesaat setelah memilih kecepatan maka kipas penyejuk ruangan akan berputar sesuai dengan kecepatan yang di pilih pengguna.

\section{HASIL DAN PEMBAHASAN}

\subsection{Implementasi}

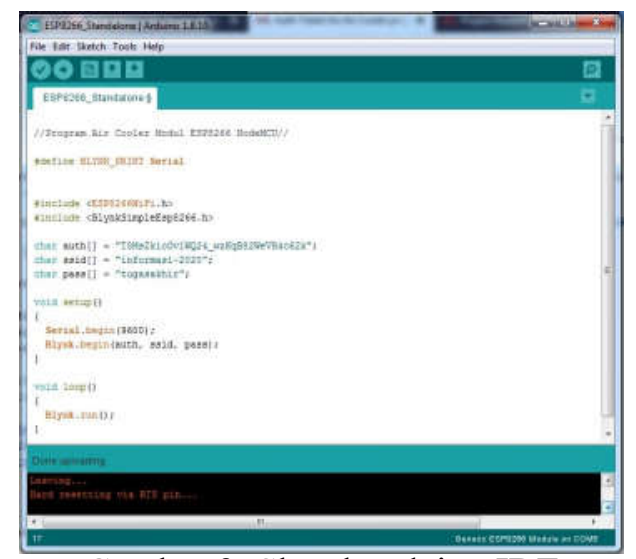

Gambar 3. Sketch arduino IDE 
Pada Gambar 3 merupakan program yang di upload ke modul ESP8266 NodeMCU V3, yang akan Terhubung langsung pada aplikasi Blynk di smartphone. Software yang dipakai memprogram NodeMCU V3 adalah dengah Aruino IDE versi 1.8.10 Bila program tersebut berhasil maka akan langsung terhubung ke internet via wifi seperti. bila dilihat pada serial monitor. Dan ketika program sudah terkirim ke board NodeMCU V3 biasanya langsung tersambung ke wifi, akan tetapi kadang ada masalah dimana board NodeMCU V3 awalnya sudah tersambung ke wifi tapi selanjutnya tiba-tiba tidak tersambung dengan sendirinya setelah dilihat di serial monitor pada software Arduino IDE nya, disebabkan ada beberapa kemungkinan yaitu antara ip nya memblock blynk nya atau aplikasi blynk nya sedang ada gangguan di server nya (M. Aluh Ashari, Lita Lidyawati. 2019).

Langkah terakhir adalah menekan tombol reset pada board ESP8266 NodeMCU, sehingga tampilan dari serial monitor pada software arduino IDE seperti pada Gambar 3 dibawah ini.

\subsection{Menggunakan Aplikasi Blynk}

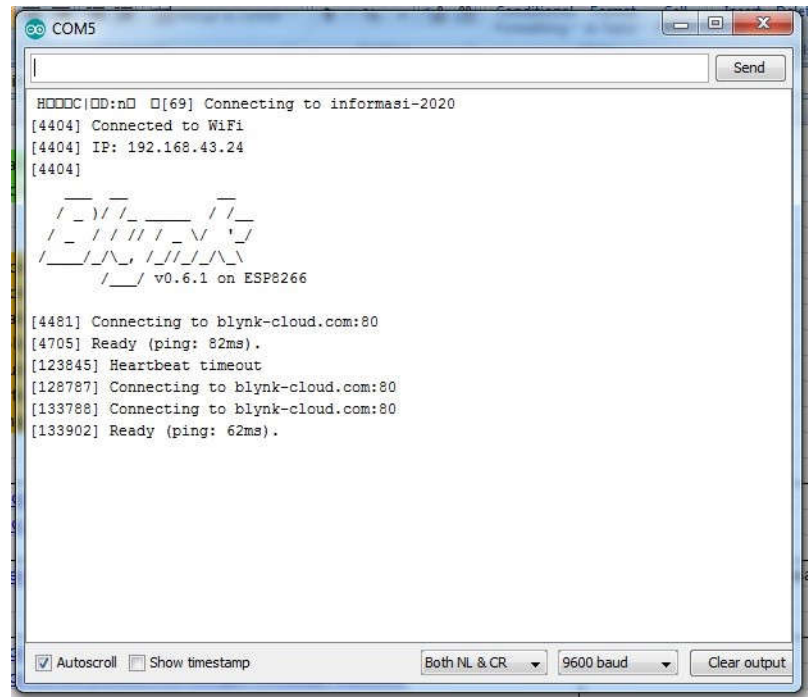

Gambar 3. Serial monitor pada aplikasi blynk

Buka aplikasi blynk pada smartphone, kemudian login dengan username dan password yang telah dibuat sebelumnya pada saat pendaftaran pengguna baru.

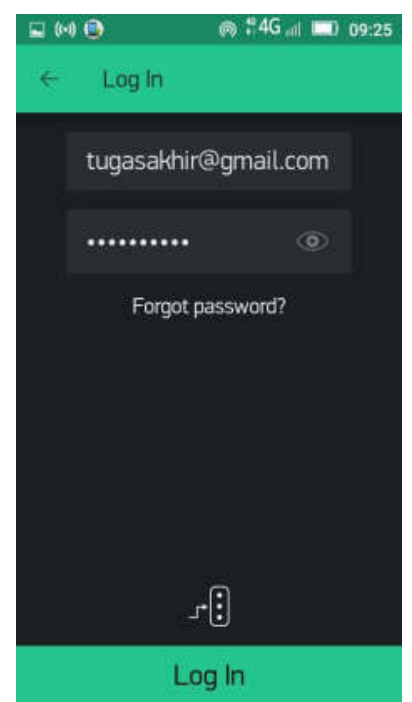

Gambar 4. Halaman Login Aplikasi Blynk

GO INFOTECH: JURNAL ILMIAH STMIK AUB Vol. 26, No. 2, Desember 2020: 186-193 
Setelah masuk ke dalam aplikasi, dilanjutkan dengan me-running aplikasi tersebut, sehingga tampilan aplikasi tampak seperti pada gambar dibawah.

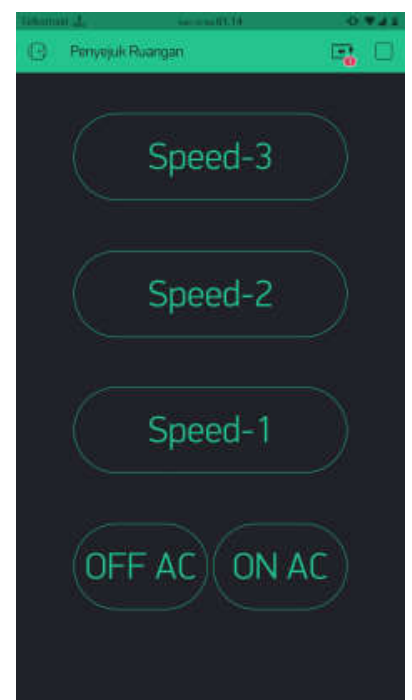

Gambar 5. Aplikasi Blynk saat running

Tahap ini sudah dapat diamati perangkat modul ESP8266 NodeMCU yang kita buat sudah terhubung dengan server blynk. Dengan ditandai notifikasi online di atas tombol speed-3.

\subsection{Pengujianalat}

Pengujian dari tahap ini merupakan pengujian dari alat secara keseluruhan, dimana dalam pengujian ini menggambarkan kerja sistem secara maksimal. Adapun hasil pengujian pada tahap ini dapat dilihat dari beberapa skenario pengujian sebagai berikut:

3.3.1 Pengujian penyejuk Ruangan

Tahapan ini dilakukan penekanan tombol OFF AC pada aplikasi blynk. Pada kondisi ini berakibat putaran kipas pada Penyejuk ruangan berhenti, di tandai dengan lampu LED mati. Seperti terlihat pada Gambar 6 di bawah ini.

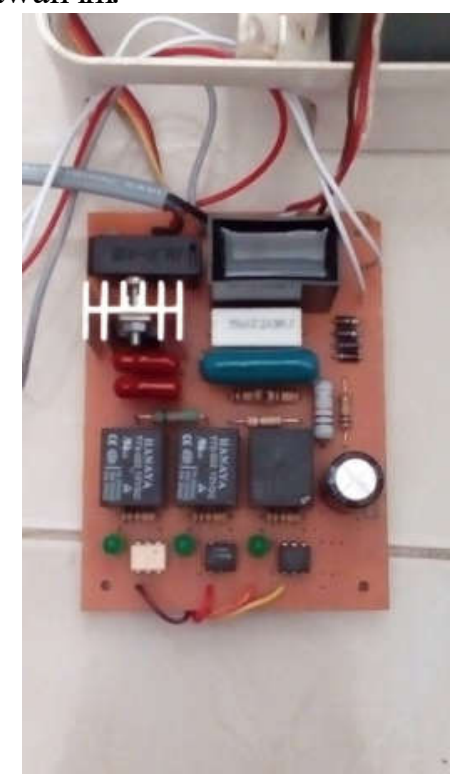

Gambar 6. Penyejuk Ruangan berhenti berputar

Pada gambar diatas modul penyejuk ruangan dalam posisi off atau kipas berhenti berputar 3.3.2 Pengujian Penyejuk Ruangan kecepatan 3 


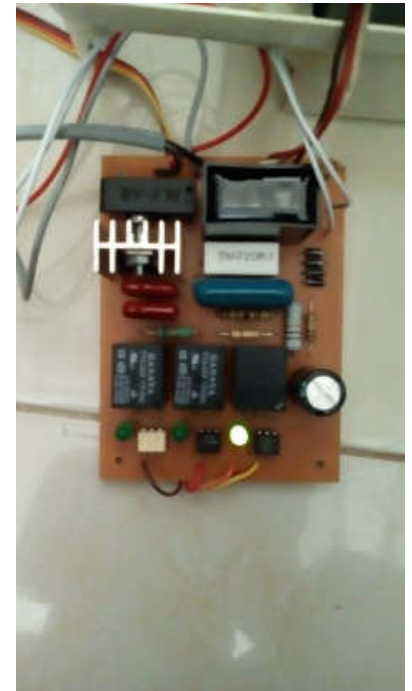

Gambar 7. Led kecepatan 3 menyala

Gambar 7 merupakan tanda bahwa penyejuk ruangan memutar kipas dalam kecepatan maksimal. Dan lampu led akan menyala sesuai dengan pilihan kecepatan, jika keceptan 1 maka led paling kiri menyala, jika kecepatan 2 maka led tengah menyala, jika kecepatan 3 maka led yang paling kanan yang akan menyala.

\section{KESIMPULAN}

Setelah beberapa tahapan dari perancangan, pembuatan dan pengujian alat telah dilalui maka dapat dibuat kesimpulan dari alat yang telah dibuat antara lain :

1. Untuk memudahkan pengendalian perangkat penyejuk ruangan agar lebih praktis dan tidak membutuhkan banyak remot kontrol untuk mengendalikan peralatan listrik lainya.

2. Sistem yang dapat diaplikasikan untuk mewujudkan kendali jarak jauh melalui jaringan internet adalah dengan menggunakan aplikasi blynk yang terhubung dengan modul ESP8266 NodeMCU V3 dengan bantuan koneksi Internet.

\section{SARAN}

Alat yang telah dibuat adalah jauh dari kesempurnaan, sehingga agar dihasilkan alat yang lebih baik dari sekarang maka dibutuhkan beberapa penyempurnaan. Oleh karena itu penulis memberikan beberapa saran untuk pengembangan alat, antara lain :

1. Tempatkan alat pada kotak permanen yang kuat dan tahan dari goncangan, sehingga rangkaian dapat berjalan dengan baik tanpa ada masalah dengan perkabelan.

2. Tambahkan fitur timer untuk mengatur waktu penggunaan.

3. Gunakan Penyejuk ruangan yang memiliki kondensor supaya udara lebih dingin.

4. Pastikan koneksi internet dari modul ESP8266 NodeMCU ke jaringan wifi adalah kencang dan stabil sehingga data dari server blynk data diterima tanpa adanya loss data.

\section{DAFTAR PUSTAKA}

[1] Arafat. 2016. Sistem Pengamanan Pintu Rumah Berbasis Internet of Things (IoT) Dengan ESP8266. Jurnal Ilmiah Fakultas Teknik, Vol. 7, No. 4, 262-268

[2] Erwan Eko Prasetiyo. 2017. Aplikasi Internet of Things (IoT) Untuk Pemantauan Dan Pengendalian Beban Listrik di Ruangan. Jurnal Teknika STTKD, Vol.4, No. 2, Desember:28-39. Program Studi DIII Aeronautika, STTKD Yogyakarta 
[3] Lulu Fikriyah dan Ajar Rohmanu. 2018. Sistem Kontrol Pendingin Ruangan Menggunakan Arduino Web Server dan Embedded Fuzzy Logic Di PT. Inoac Polytechno Indonesia. Jurnal Informatika SIMANTIK, Vol. 3 No. 1, Maret: 21-27. Program Studi Teknik Infornatika, STMIK Cikarang

[4] M. Aluh Ashari dan Lita Lidyawati. 2019. IoT Berbasis Sistem Smart Home Menggunakan Nodemcu V3. Ejournal Kajian Teknik Elektro, Vol. 3 No.2 SeptemberFebruari: 138-149. Program Studi Teknik Elektro, Institut Teknologi Nasional, Magister Teknik Elektro, Universitas 17 Agustus 1945 Jakarta

[5] Mehta, Mannan. 2015. "Esp 8266: A Breakthrough In Wireless Sensor Networks And Internet Of Things". International Journal of Electronics and Communication Engineering \& Technology, Vol. 6, Issue 8, August: 07-11. ARK Techno solutions, Mumbai, India

[6] Mochamad Fajar Wicaksono. 2017. Implementasi modul Wifi NodeMCU ESP8266 Untuk Smart Home. Jurnal Teknik Komputer Unikom. Vol. 6, No. 1, September: 1-6. Jurusan Teknik Komputer, UNIKOM, Bandung

[7] R. Muzawi, Y. Efendi, \& W. Agustin. 2018. Sistem pengendalian Lampu Berbasis Web dan Mobile. Sains dan Teknologi Informasi, Vol. 4, No. 1, 30-35

[8] Sugiyono. 2013. Metode Penelitian Kualitatif, Kuantitatifdan $R \& D$. Cetakan ke-19. Bandung : Alfabeta.

[9] Sadewo, Angger Dimas Bayu., Widasari, Edita Rosana ., \& Muttaqin, Adharul. (2017). Perancangan Pengendalian Rumah Menggunakan smartphone Android Dengan Konektivitas Bluetooth. Jurnal Pengembangan Teknologi Informasi dan Ilmu Komputer, Vol. 1, No. 5, 415-425.

[10] Tresna Widiyaman. 2016. Pengertian Modul Wifi ESP8266. http://www.warriornux.com/pengertia n-modul-wifi-esp8266/ (diakses tanggal 8 Februari 2020) 